\title{
Numerical Analysis on Anti-galloping VED of Transmission Lines
}

\author{
Chao-qun Liu ${ }^{1,2, a}, \mathrm{Na} \mathrm{Sun}^{2, \mathrm{~b}}$, Kuan-jun $\mathrm{Zhu}^{2, \mathrm{c}}$, \\ Sheng-chun Liu $^{2, \mathrm{~d}}$, Liang-hu Jiang ${ }^{2, \mathrm{e}}$ \\ ${ }^{1}$ School of Mechanical Engineering, \\ Xi'an Jiaotong University, \\ Xi'an, 710049, China \\ ${ }^{2}$ China Electric Power Research Institute, \\ Beijing, 102401, China \\ aliuchaoqun@epri.sgcc.com.cn, ${ }^{\mathrm{b}}$ sunn@epri.sgcc.com.cn, \\ 'zhukuanjun@epri.sgec.com.cn, \\ dliushengchun@epri.sgcc.com.cn, \\ jianglianghu@epri.sgcc.com.cn
}

\author{
Ling-zhi $\mathrm{Xu}^{3, \mathrm{f}}$, Zhao-dong $\mathrm{Xu}^{3, \mathrm{~g}}$ \\ ${ }^{3}$ Southeast University, \\ Key Laboratory of Concrete and Prestressed Concrete \\ Structures of the Ministry of Education, \\ Nanjing, 210096, China

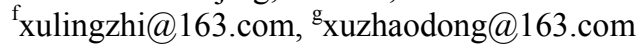

\begin{abstract}
A 2-DOF model with the coupling of vertical and torsional motions is considered to study galloping of transmission lines in this paper. Based on Lagrange equation, the equation of motion is established. dynamic analysis is obtained by using Newmark- $\beta$ method in an example. Finally, anti-galloping VED is used to investigate its effect of vibration control.
\end{abstract}

Keywords-transmission lines; galloping; 2-DOF model; anti-galloping VED; numerical analysis

\section{FOREWORD}

Galloping of iced transmission line is a typical low-frequency (about $0.1 \sim 3 \mathrm{~Hz}$ ), large amplitude (about $5 \sim 300$ times of the diameter of the wire) of the self-excited vibration of gas-solid coupling phenomenon. When galloping, all-speed wire do directional wave undulating movement. Due to large amplitude, long - time vibration is easy to cause flashover, seriously causing fitting damage, line tripped, tower failure, etc[1-2].

Since the 1920s, national science and technology workers have carried out extensive research and achieved fruitful results about galloping in the theoretical analysis and experimental verification. In galloping mechanism, Den Hartog wave vertical excitation mechanism[3] of the United States and O. Nigol torsional excitation mechanism[4] of Canadian are still the mainly ones, the studies of other mechanism and anti - galloping measures are based on the two theories; In Experiment, wind tunnel test is mainly used to test the aerodynamic coefficients of iced conductors, wind tunnel simulation test of galloping with iced line is considerable difficultly carried out. To study test line is undoubtedly the most direct method for galloping, but the observation time long and expensive. Numerical simulation research has been an important means of galloping problem. Currently, there are single-degree-of- freedom model of vertical, 2-dof model of vertical and torsional coupling, as well as 3-dof model of vertical, horizontal and torsional coupling[5] used to study galloping. The 2-dof model, not only taking into account the Den Hartog vertical galloping theory and
Nigol torsional galloping theory, but also ignoring the minor horizontal movement, is simple, easy to be carrid out dynamic characteristics analysis for wire.

According to statistics, the current anti-galloping devices[6-9] of domestic transmission line include double pendulum anti-galloping device, rotating clamp spacer, phase spacer and so on, they all achieve good anti-galloping effect in practice, they work mostly by changing line structure and parameters. According to mechanism of galloping, whether Den Hartog vertical excitation mode or Nigol torsional excitation mode, galloping inspire is dynamic instability phenomenon caused by negative damping energy accumulation of wire system, so the conductor structural damping is one of the important characteristic parameters of galloping, the source of galloping in the inherent characteristics of the structure. Adding wire damping structure and dissipating wind power of wire system is a fundamental way to inhibit galloping. In this paper, the anti-galloping of VED, with the energy dissipation capability of viscoelastic materials and the TMD effect[10-12], increase the damping of the wire and effectively inhibit galloping of wire.

In this paper, the galloping of wire is studied with 2-dof degree of vertical and torsional coupling and Newmark- $\beta$ dynamic analysis methods, the anti-galloping VED is joined, the mathematical model is proposed, and damping effect is theoretically analyzed.

\section{2-DOF MODEL OF THE WIRE}

\section{A. Dynamic Balance Equation of Wire without Anti-galloping VED}

The 2-dof model is described by the use of the whole fixed coordinate system Y-O-Z and local moving coordinate system Ya-a-Za, as shown in Figure 1. The origin of $\mathrm{Ya}-\mathrm{a}-\mathrm{Za}$ is located in the center of rotation a, the rotation angle of the moving coordinate system around a is described by $\theta_{t}$. 


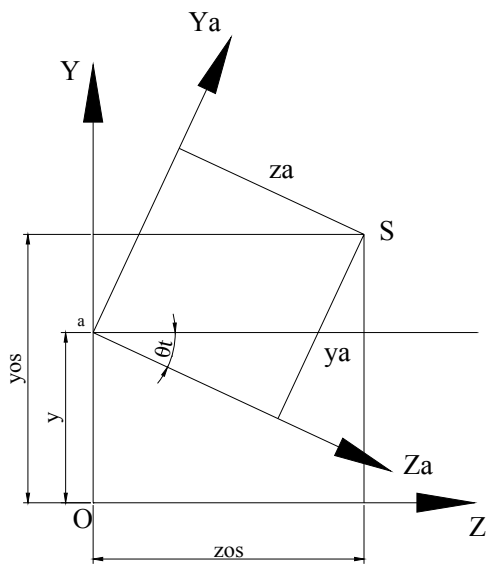

Figure 1. 2-DOF-model coordinate system

The coordinate of any point $\mathrm{S}$ on iced wire (Figure 1) in the local moving coordinate system is ( $\mathrm{za}$, ya ), the rotation angle of its is $\theta_{t}$, then the coordinate of its in the whole fixed coordinate system is,

$z_{o s}=z_{a} \cos \theta_{t}+y_{a} \sin \theta_{t}$

$y_{o s}=y+y_{a} \cos \theta_{t}-z_{a} \sin \theta_{t}$

When $\theta_{t}$ is small enough, equation (1) can be approximated by the value of

$z_{\text {os }}=z_{a}+y_{a} \theta_{t}$

$y_{o s}=y+y_{a}-z_{a} \theta_{t}$

The dericative $t$ to Equation (2) on both sides is $\dot{z}_{\text {os }}$ and $\dot{y}_{o s}$, so the per unit length kinetic-energy of the iced wire is,

$$
T=\frac{1}{2} \int_{A}\left(\dot{y}_{o s}^{2}+\dot{z}_{o s}^{2}\right) \rho d A
$$
is,

The per unit length potential-energy of the iced wire

$$
V=\frac{1}{2}\left(k_{y} y^{2}+k_{t} \theta_{t}^{2}\right)
$$

Where, $k_{y}$ is the wire vertical stiffness, $k_{t}$ is the wire torsional stiffness.

The per unit length non-conservative force of the iced wire is,

$$
\begin{aligned}
& Q_{y}=F_{y}-2 m \varsigma_{y} \omega_{y} \dot{y} \\
& Q_{t}=M_{t}-2 J \varsigma_{t} \omega_{t} \dot{\theta}_{t}
\end{aligned}
$$

Equation (3), (4), (5) into the Lagrange equation,

$$
\frac{d}{d t}\left(\frac{\partial T}{\partial \dot{q}_{i}}\right)-\frac{\partial T}{\partial q_{i}}+\frac{\partial V}{\partial \dot{q}_{i}}=Q_{i}
$$

The dynamic equilibrium equation of the 2-dof model of the iced wire is,

$$
\begin{gathered}
m \ddot{y}+2 m \varsigma_{y} \omega_{y} \dot{y}-S \ddot{\theta}_{t}+k_{y} y=F_{y} \\
J \ddot{\theta}_{t}+2 J \varsigma_{t} \omega_{t} \dot{\theta}_{t}-S \ddot{y}+k_{t} \theta_{t}=M_{t}
\end{gathered}
$$

This model is mainly used to study the coupling problem between vertical freedom and torsional freedom of the conductor. The bundle conductors are mainly studied in this paper, the whole span conductors are simplified to be a particle in the middle of the span, the amplitude and the dynamic properties of this point adding anti-galloping VED are studied for the studies of future multi-particle calculations. In Equation (7), $\mathrm{m}$ is the equivalent mass of the bundle conductor at its midpoint of the span, $\mathrm{J}$ is the equivalent moment of inertia, $S$ is equivalent eccentric moments, $\varsigma_{y}, \varsigma_{t}$ is respectively the vertical and the torsional damping ratio, $\omega_{y}, \omega_{t}$ is respectively the vertical and the torsional natural frequency, $F_{y}, M_{t}$ is respectively the vertical and the torsional aerodynamics force, it can be expressed as

$$
\begin{aligned}
& F_{y}=\frac{n}{2} \rho U^{2} D C_{y} L \\
& M_{t}=\frac{n}{2} \rho U^{2} D^{2} C_{t} L
\end{aligned}
$$

Where, $\rho$ is the air density, $U$ is the wind speed, $D$ is the height of the conductor vertical to the direction of flow, $L$ is the length of the conductor, $C_{y}, C_{t}$ is respectively the vertical and the torsional aerodynamic coefficient, so, based on the wind tunnel test datas, it can be expressed as [5] [13]

$$
\begin{aligned}
& C_{y}=\alpha_{1} \theta+\alpha_{2} \theta^{3} \\
& C_{t}=\beta_{1} \theta+\beta_{2} \theta^{3}
\end{aligned}
$$

Where, $\alpha_{1}=-1.6478, \alpha_{2}=0.1761, \beta_{1}=0.3592$, $\beta_{2}=-0.0434, \theta=\theta_{0}-\dot{y} / U, \theta_{0}$ is the Horizontal angle of the icing.

\section{B. Dynamic Balance Equation of Wire with Anti-galloping VED}

With the above Lagrange equation, the dynamic balance equation of wire with anti-galloping VED can be derived with reference to the dynamic balance equation of Structure with TMD [10] [14],

$$
\begin{aligned}
& m \ddot{y}+\left(2 m \varsigma_{y} \omega_{y}+c_{d}\right) \dot{y}+\left(k_{y}+k_{d}\right) y \\
& -c_{d} \dot{y}_{d}-k_{d} y_{d}-S \ddot{\theta}_{t}=F_{y} \\
& J \ddot{\theta}_{t}+2 J \varsigma_{t} \omega_{t} \dot{\theta}_{t}-S \ddot{y}+k_{t} \theta_{t}=M_{t} \\
& m_{d} \ddot{y}_{d}+c_{d}\left(\dot{y}_{d}-\dot{y}\right)+k_{d}\left(y_{d}-y\right)=0
\end{aligned}
$$


Where, $m_{d}, c_{d}, k_{d}$ is respectively the mass, the damping and the stiffness of the anti-galloping mechanism, $\ddot{y}_{d}, \dot{y}_{d}, y_{d}$ is respectively the acceleration, the velocity and the displacement of the anti-galloping mechanism, the rest coefficients are the same with the ones without anti-galloping mechanism.

\section{VIBRATION REDUCING ANALYSIS OF THE CONDUCTOR GALLOPING}

\section{A. The Example}

In this paper, the coefficients of icing conductos are shown in Table I, the calculation is carried out with the above 2-dof model, and the dynamic characteristics of the conductor were compared.

TABLE I. COEFFICIENT TABLE FOR ICED CONDUCTOR

\begin{tabular}{|c|c|c|c|}
\hline Unit Mass of the Conductor $m_{L}$ & $3 \mathrm{~kg} / \mathrm{m}$ & Conductor Tension $T$ & $40000 \mathrm{~N}$ \\
\hline Conductor Diameter $d$ & $28 \mathrm{~mm}$ & The Thickness of Icing $h$ & $15 \mathrm{~mm}$ \\
\hline Conductor Length $L$ & $200 \mathrm{~m}$ & Wind Speed $U$ & $10 \mathrm{~m} / \mathrm{s}$ \\
\hline Conductor Spacing $a$ & $0.6 \mathrm{~m}$ & Air Density $\rho$ & $1.29 \mathrm{~kg} / \mathrm{m}^{3}$ \\
\hline Vertical Damping Rratio $S_{y}$ & 0.06 & Icing Density $\rho_{i}$ & $900 \mathrm{~kg} / \mathrm{m}^{3}$ \\
\hline Horizontal angle of Icing $\theta_{0}$ & $\pi / 4$ & The No. of Conductors $n$ & 3 \\
\hline Torsional Damping Rratio $S_{t}$ & 0.06 & Torsional Stiffness of Single Conductor $k_{t s}$ & $400 \mathrm{Nm} / \mathrm{rad}$ \\
\hline
\end{tabular}

In this paper, coefficients of bundled conductors can be expressed as [2] [3],

$$
\begin{aligned}
& m_{i}=\frac{\pi}{4} \rho_{i} h d \\
& m=\frac{4 n L\left(m_{i}+m_{L}\right)}{\pi^{2}} \\
& J=\frac{4 n L\left(m_{i}+m_{L}\right) L a^{2}}{\pi^{2}} \\
& k_{y}=4 n T / L \\
& k_{t}=\frac{4 n}{L}\left(\frac{T d^{\prime 2}}{4}+k_{t s}\right) \\
& S=\frac{2 n L m_{i} L(d+h)}{\pi^{2}} \\
& d^{\prime}=\frac{a}{2 \cos 30^{\circ}} \\
& D=d+h \sin \theta_{0}
\end{aligned}
$$

Where, $d^{\prime}$ is the equivalent diameter of bundle conductors.

\subsection{The Results}

According to the datas shown in Table 1, with the Newmark- $\beta$ iterative analysis method [15-17], and joined the anti-galloping VED, $c_{d}=16.13 \mathrm{~N} \cdot \mathrm{s} / \mathrm{m}, k_{d}=$ $52000 \mathrm{~N} / \mathrm{m}$, the results of dynamic characteristics of the conductor compared are shown in Figure 2 and 3.

It is showed that, in Figure 2 and 3, the use of 2-dof model, combined with Newmark- $\beta$ method, vertical vibrations decrease of about $50 \%$ with anti-galloping VED as changes in displacement and rotational angle with time under the influence of particular wind speed. And because of the coupling of the vertical and torsional degree of freedom, the rotation angle reduced by about $70 \%$. It is showed that anti-galloping VED has good damping effect.

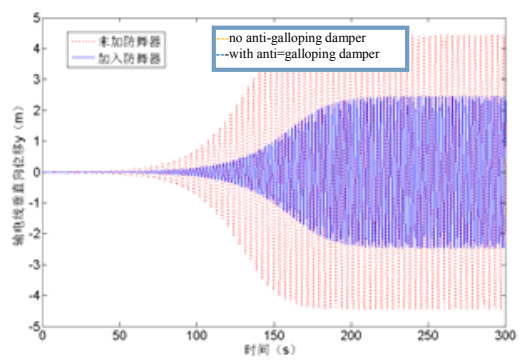

Figure 2. Vertical displacement comparison

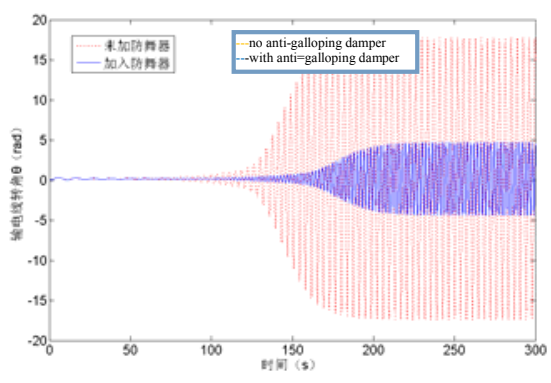

Figure 3. Torsionall displacement comparison 


\section{CONCLUSION}

In this paper, with 2-dof model of the vertical and torsional degree of freedom coupling, combined with Newmark- $\beta$ dynamic analysis method, the galloping of the conductor is studied and the mathematical model is analyzed its damping effect theoretically with anti-galloping VED.

The 2-dof model of conductor galloping, not only ignoring the secondary level movement, but also reflecting the coupling of the degree of freedom of vertical and torsional, is relatively simple, it can simulate changes in displacement and rotation with time under the influence of particular wind speed.

In this paper, the theory of the anti-galloping VED is the energy consumption of the viscoelastic material and the TMD effect on the wire. It is showed that anti-galloping VED has good damping effect with vertical vibrations decreased of about $50 \%$ and the rotation angle reduced by about $70 \%$.

\section{REFERENCES}

[1] JIANG Xing-liang, SUN Cai-xin, WANG Shao hua. Study status of conductor galloping on transmission line $[\mathrm{J}]$. High Voltage Engineering, 2005, 31(10): 11-14.

[2] Guo Ying-long, Li Guo-xing, You Chuan-yong. Transmission Line Galloping[M]. Beijing: China Electric Power Press, 2003.

[3] J. P. Den Hartog. Transmission line vibration due to sleet[J].Trans AIEE, 1932, 51(4): 1074-1086.

[4] O. Nigol, G. J. Clarke and D. G. Havard. Torsional stability of bundle conductors[J]. IEEE Trans. Power App. and Sys., 1977(96): 1666-1674.

[5] P. Yu, Y. M. Desai and N. Popp.l ewell. Three-degree-of-freedom model for galloping. Part 2: solutions[J]. J. Eng. Mech, 1993(119):
$2426-2448$.

[6] M. L. Lu, N. Popplewell, A. H. Shah and J. K. Chan. Hybrid Nutation Damper for Controlling Galloping Power Lines[J]. IEEE Tranctions on Power Delivery, 2007, 22(1): 450-456.

[7] A.J.Carreira. Controlling Conductor Motion with Interphase Spacers in Regions of Contamination[J]. IEEE Electrical Insulation Magazine, 2008, 24(6): 35-42.

[8] M. D. Rowbottom, B. Sc., Ph.D., C. Eng, F.I.M.A., M.I.E.E., and J.G. Allnutt, B. Sc., D. Phil. Mechanical dampers for the control of full span galloping oscillations[J]. IEE PROC., 1982, 129(3): 123-135.

[9] Lilien, J.L. and A. Vinogradov. Full-scale Teats of TDD Antigalloping Device (Torsional Damper and Detuner). IEEE Transactions on Power Delivery, 2002, 17(2): 638-643.

[10] Xu Zhao-dong, Ma Le-wei. Structural Dynamics[M]. Beijing: Science Press, 2007.

[11] Li Ai-qun. Structure Vibration Control[M]. Beijing: China Machine Press, 2007.

[12] Liu Yan-zhu, Chen Wen-liang, Chen Li-qun. Vibration Mechanics[M]. Beijing: China Higher Education Press, 1998.

[13] Fan Qin-shan, Guan Fei, Zhao Kun-ming, et al. The mechanism analysis and dynamic simulation of iced conductor galloping[J]. Journal of Tsinghua University (Sci \& Tech ), 1995, 35(2): 34-40.

[14] Chen Xiaoming, Deng Hongzhou, Wang Zhaomin. Conductor Galloping Stability Analysis of Long-span Transmission System[J]. Engineering Mechanics, 2004, 21(1): 56-60.

[15] M. F. Dimentberg and A. Hera;A. Naess. Marginal Instability and Intermittency in Stochastic Systems-Part I: Systems With Slow Random Variations of Parameters[J]. Journal of Applied Mechanics, 2008, 75: 041002-1 041002-8.

[16] Q. Zhang, N. Popplewell, and A. H. Sgah, "Galloping of bundle conductor", J. Sound Vibr., vol. 234, pp. 115-134,2000.

[17] Yamaguchi H., C.B. Gurung and T. Yukino, "Characterization of wind-induced vibration in transmission lines by single-channel field data analysis", Proc. of the 5th Int. Symposium on Cable Dynamics, Santa Margherita(Italy), September 2003(15-18). 